\title{
Continuous monitoring of intracranial compliance in neurointensive care (Editorial by invitation)
}

\author{
Per Enblad ${ }^{1}$ (D) \\ Received: 16 September 2018 / Accepted: 17 September 2018 / Published online: 17 October 2018 \\ (C) Springer-Verlag GmbH Austria, part of Springer Nature 2018
}

Evaluation of intracranial compliance, i.e. the ability to compensate for increased intracranial volume (e.g. due to an extracerebral haematoma, contusions or brain oedema) may add valuable information to routine ICP monitoring in neurointensive care. The Monroe-Kellie doctrine provides the basis for the volume-pressure interaction stating that under normal physiological conditions, the total volume of the three compartments in the rigid skull (circulating blood, brain and CSF) is constant and if the volume of one compartment is increasing, this is compensated by a decrease in volume of another department. With an increase in lesion volume, the total intracranial volume is initially kept constant by reductions in blood volume (due to vasocompression), and through displacement of CSF. When this volume compensatory reserve is exhausted, ICP increases exponentially. Compliance refers to the magnitude of the change in pressure induced by an increase in volume $(\Delta \mathrm{V} / \Delta \mathrm{P})$, and indicates where the patient is on the pressure-volume curve.

It has long been considered important to gain information about the intracranial compensatory reserve in neurointensive care of acute brain injury. Such information would make it possible to identify in advance patients with low compliance who are at risk of developing high ICP. If those patients receive special attention and preventive management, an ICP increase and related secondary brain injury may be avoided. The individualized management to avoid an ICP increase and to detect complications requiring acute surgical treatment may for example include caution with wake-up tests, deeper sedation and more analgesics, closer pupillary examinations and more frequent CT scanning. The risk of inducing ICP insults

This article is part of the Topical Collection on Neurosurgical intensive care

Per Enblad

Per.Enblad@neuro.uu.se

1 Department of Neuroscience/Neurosurgery, Uppsala University Hospital, SE-751 85 Uppsala, Sweden in relation to nursing interventions (e.g. repositioning of the patients, oral care, endotracheal suction) should also be considered in patients with low compliance. The most important nursing interventions should be prioritized and carefully planned with extra sedation and pain relief before the intervention is initiated.

Early methods investigated the volume-pressure relationship directly by injecting or withdrawing small volumes ( $1 \mathrm{ml}$ ) of fluid into the ventricular catheter while the ICP changes was recorded $[8,9]$. This technique provided direct knowledge about the volume-pressure relationship, but it was difficult to use in clinical routine. Furthermore, it was not a continuous measure, and there were safety concerns $[1,12]$. The Spiegelberg compliance monitor provided continuous estimates of compliance by automated calculation of average values in a moving time-window from repeated injections (and withdrawals) of small volumes into a balloon at the tip of a ventricular catheter but the technique was associated with considerable technical problems $[5,11,14]$. Various continuous measures based on the ICP waveform have also been evaluated such as the ICP pulse amplitude [1, 13], the ascending slope of the ICP pulse waveform $[2,12]$ and the RAP index $[3,6]$, which is the moving correlation between mean ICP and the ICP pulse amplitude over a time window of about 4 min. Occurrence of A waves (plateau waves) and B waves (pressure peaks of $10-20 \mathrm{mmHg}$ at a rate of $0.5-2 / \mathrm{min}$ ), which Lundberg described in the 1960s [7], are also considered to be related to low compliance. Still there is no consensus on how best to measure compliance in the clinical setting, and therefore studies which aim at evaluating the potential information provided by these and other measures of compliance are welcome. One approach that has been used previously is to study the effects on proposed compliance metrics of treatments that reduce the intracranial volume (e.g. mannitol and steroid therapy [10], thiopental treatment and surgical evacuation of haematoma [4]), or that increase the cranial volume (i.e. decompressive craniectomy [4]). In the paper from the Cambridge group by Zeilar and colleagues in this 
issue of Acta Neurohirurgica, the RAP index, developed by Czosnyka and colleagues in the 1990s [3], was found to be associated with cerebral CT injury patterns of diffuse injury and edema, providing further evidence that the RAP index is a valid measure of cerebral compensatory reserve. Furthermore, the study demonstrates that relating the amount of CSF on brain $\mathrm{CT}$, as an estimation of compensatory reserve, to a measure of compliance at the time of the CT scanning may be a valuable method to validate different continuous measures of intracranial compliance.

\section{References}

1. Avezaat CJ, van Eijndhoven JH, Wyper DJ (1979) Cerebrospinal fluid pulse pressure and intracranial volume-pressure relationships. J Neurol Neurosurg Psychiatry 42:687-700

2. Contant CF Jr, Robertson CS, Crouch J, Gopinath SP, Narayan RK, Grossman RG (1995) Intracranial pressure waveform indices in transient and refractory intracranial hypertension. J Neurosci Methods 57:15-25

3. Czosnyka M, Price DJ, Williamson M (1994) Monitoring of cerebrospinal dynamics using continuous analysis of intracranial pressure and cerebral perfusion pressure in head injury. Acta Neurochir 126:113-119

4. Howells T, Lewen A, Skold MK, Ronne-Engstrom E, Enblad P (2012) An evaluation of three measures of intracranial compliance in traumatic brain injury patients. Intensive Care Med 38:10611068. https://doi.org/10.1007/s00134-012-2571-7

5. Kiening KL, Schoening WN, Lanksch WR, Unterberg AW (2002) Intracranial compliance as a bed-side monitoring technique in severely head-injured patients. Acta Neurochir Suppl 81:177-180
6. Kim DJ, Czosnyka Z, Keong N, Radolovich DK, Smielewski P, Sutcliffe MP, Pickard JD, Czosnyka M (2009) Index of cerebrospinal compensatory reserve in hydrocephalus. Neurosurgery 64:494 501; discussion 501-492. https://doi.org/10.1227/01.NEU. 0000338434.59141 .89

7. Lundberg N (1960) Continuous recording and control of ventricular fluid pressure in neurosurgical practice. Acta Psychiatr Scand Suppl 36:1-193

8. Marmarou A, Shulman K, LaMorgese J (1975) Compartmental analysis of compliance and outflow resistance of the cerebrospinal fluid system. J Neurosurg 43:523-534. https://doi.org/10.3171/jns. 1975.43.5.0523

9. Miller JD, Garibi J, Pickard JD (1973) Induced changes of cerebrospinal fluid volume. Effects during continuous monitoring of ventricular fluid pressure. Arch Neurol 28:265-269

10. Miller JD, Leech P (1975) Effects of mannitol and steroid therapy on intracranial volume-pressure relationships in patients. $J$ Neurosurg 42:274-281. https://doi.org/10.3171/jns.1975.42.3. 0274

11. Piper IR, Miller JD, Whittle IR, Lawson A (1990) Automated timeaveraged analysis of craniospinal compliance (short pulse response). Acta Neurochir Suppl (Wien) 51:387-390

12. Robertson CS, Narayan RK, Contant CF, Grossman RG, Gokaslan ZL, Pahwa R, Caram P Jr, Bray RS Jr, Sherwood AM (1989) Clinical experience with a continuous monitor of intracranial compliance. J Neurosurg 71:673-680. https://doi.org/10.3171/jns.1989. 71.5.0673

13. Wilkinson HA, Schuman N, Ruggiero J (1979) Nonvolumetric methods of detecting impaired intracranial compliance or reactivity: pulse width and wave form analysis. J Neurosurg 50:758-767. https://doi.org/10.3171/jns.1979.50.6.0758

14. Yau Y, Piper I, Contant C, Citerio G, Kiening K, Enblad P, Nilsson P, Ng S, Wasserberg J, Kiefer M, Poon W, Dunn L, Whittle I (2002) Multi-centre assessment of the Spiegelberg compliance monitor: interim results. Acta Neurochir Suppl 81:167-170 